REVISTA ANDALUZA DE ANTROPOLOGÍA.

NÚMERO 4: ENCRUCIJADAS PARA LAS SOCIEDADES PESQUERAS DEL SUR EN EL MARCO DE LA GLOBALIZACIÓN. MARZO DE 2013

ISSN 2174-6796

[pp. 186-191]

http://dx.doi.org/10.12795/RAA.2013.i04.12

\title{
MORENO, ISIDORO Y AGUDO, JUAN (Coord.) (2012). Expresiones culturales andaluzas. Sevilla: Aconcagua Libros, 324 pp.
}

\author{
Assumpta Sabuco Cantó \\ Universidad de Sevilla
}

Néstor García Canclini aseguraba que "El siglo XX fue el siglo del ascenso y el fracaso de las revoluciones contra la desigualdad. Fue también, en un sentido menos épico y con caídas menos estrepitosas, el siglo del reconocimiento de la diversidad" (2011: 103). El presente siglo oscila entre valorar las diferencias o negarlas provocando con ello un nuevo desorden en el que se favorecen o multiplican las desigualdades. Frente al auge que están adquiriendo, en el lenguaje político, términos ligados al choque o a las alianzas entre civilizaciones, la publicación de este libro coordinado por Isidoro Moreno y Juan Agudo retoma la centralidad del concepto "cultura" y de sus manifestaciones. Con una clara voluntad de difundir modelos de conocimiento más sólidos y productivos, se explicitan marcos teóricos y metodológicos capaces de reconducir los nuevos debates sobre las diferencias y la igualdad hacia una hermenéutica más sólida.

La pertinencia de esta obra es, por un lado, la gran necesidad de este tipo de aproximaciones a la realidad y, por otro, ofrecer un conocimiento gestado en Andalucía con un claro posicionamiento reivindicativo. Mostrar la vigencia de un concepto tan central en la antropología como el de las expresiones culturales refuerza la eficacia de un saber que no se pretende esencialista u homogéneo sino, al contrario, un saber que subraya la necesidad de enfocar la dicotomía entre igualdad /diferencia en un marco más amplio y más consciente. Si Catherine MacKinnon empleó el feminismo en su crítica hacia el Estado ylos poderes institucionales en busca de una transformación social, la compilación de artículos realizada por Isidoro Moreno y Juan Agudo resignifican la identidad cultural 
mediante una crítica apasionada y apasionante a la modernidad y a sus epistemologías. El objetivo, soñar con raíces que vuelen y alas que arraiguen coincidiendo con Juan Ramón Jiménez que, de esta forma tan bella y expresiva, condensa los significados de la obra. Una tradición que se expresa viva y en constante movimiento, como lo es también la tradición investigadora creada por los autores en sus respectivas especialidades y que han ido forjando nuevas ramas temáticas con nuevos científicos.

En nuestros días, el conocimiento comprometido es cada vez menos frecuente. Por ello hay que celebrar la publicación en colaboración con el Centro de Estudios Andaluces de una obra donde las voces se alzan claras y firmes; las voces de los investigadores, pero también de los individuos que conforman un pueblo. En la presentación, hay un posicionamiento que comparten el resto de artículos: la modernización no puede ni debe entenderse como un desarrollo inevitable hacia una sociedad más justa e igualitaria. Esta formulación es un medio de ocultamiento para eliminar pueblos y aislar a los individuos; una estrategia del sistema económico y social dominante para deshumanizar y acrecentar las desigualdades. Frente a las prisas que se imponen a los procesos de investigación, la disminución de presupuesto o la búsqueda de impacto en revistas de difícil acceso, esta obra se rebela contra los cambios bruscos en la gestión y creación de saberes que estamos experimentando y contra las temáticas ajenas de manera creciente a los sentimientos y objetivos colectivos, a los pueblos. Permite disfrutar de la mirada y el compromiso específico de los autores que han abordado el estudio de las identidades culturales en sus dilatadas trayectorias académicas y profesionales.

Este primer volumen revisa los marcadores culturales más relevantes de la cultura andaluza mientras que un segundo tomo, a cargo de José Hurtado Sánchez y Celeste Jiménez de Madariaga, caracteriza la sociedad andaluza y su funcionamiento. Unos marcadores seleccionados por su carácter nuclear en la identidad andaluza: rasgos estructurales, habla, modos de sociabilidad, arquitectura, fiestas y rituales, oficios y actividades. El conjunto de artículos expone y reivindica un modo de sentir diferencial, propio, andaluz desde una voluntad de saber que ha germinado en dos importantes grupos de investigación reconocidos tanto desde el ámbito académico como en el plano social. Nos referimos a GEISA, Grupo para el Estudio de las Identidades Socioculturales de Andalucía, bajo la dirección de Isidoro Moreno que desde los años 90 ha visto multiplicada su composición y los ámbitos de estudio, como al Grupo de Investigación Social y Acción Participativa GISAP, de la Universidad Pablo de Olavide, dirigido por Javier Escalera. En ambos casos la creciente vinculación con universidades europeas del Sur y latinoamericanas se sitúa en la resistencia a los centros de poder y en la potencialidad de crear nuevos paradigmas en el conocimiento.

En el primer capítulo, Isidoro Moreno expone los presupuestos teóricos y los conceptos fundamentales desde los que entender la identidad andaluza. Por un lado, reivindica la 
defensa de las identidades culturales de los pueblos entroncándola con la propia tradición antropológica que, en palabras de Lévi-Strauss, obliga a recordar que el ser humano no desarrolla su naturaleza en una humanidad abstracta sino dentro de culturas tradicionales. Por otro, se apoya en la "Declaración sobre los derechos culturales" elaborada por el grupo de Friburgo, que asegura el derecho a la dignidad, a la libertad, a la memoria y a los proyectos de un pueblo, definido como unidad dialéctica donde se aúna lo particular/ universal, el proceso/resultado y la diversidad/cohesión. El concepto de matriz identitaria de Isidoro Moreno ha sido notablemente validado desde sus primeras formulaciones. A nivel teórico, especialmente relevante es el capítulo publicado en Antropología de los pueblos de España en 1991 y las sucesivas elaboraciones con las que ha ido precisando su propuesta. A nivel práctico, la eficacia conceptual y epistemológica se sustenta en los trabajos etnográficos que ha publicado y dirigido. La necesidad de articular la etnicidad con el sistema sexo- género y con las culturas del trabajo se sintetiza de forma clara en el segundo epígrafe. Identidad y tradición adquieren un peso vertebrador contra las modas intelectuales que abogan por una ciudadanía aparentemente mundial e igualitaria, desmemoriada ya que son los sentimientos de pertenencia, el contraste entre nosotros/ ellos los que confieren una especificidad frente a los otros. Los rasgos estructurales básicos de la identidad andaluza son: el antropocentrismo que personaliza y humaniza las relaciones sociales; la ideología igualitarista que niega cualquier inferioridad real o simbólica y la actitud relativista. Tres aspectos que redundan en las formas de expresión con que se mantiene un capital simbólico específico y dan cuentan de las expresiones de sociabilidad, de las manifestaciones artísticas, de unos modos de sentir personales y colectivos. Unas formas, cuyos significados han sido despojados por las miradas de los otros que en el proceso de apropiación, proyectan desde Europa y desde el Estado Español, visiones deterioradas y tipificadoras. Una vampirización, según la acertada expresión del autor, que en la era de la globalización precisa de una contestación y una mayor toma de conciencia para construir una identidad de resistencia (Castells, 1998). Moreno detalla las causas de un nacionalismo deficitario políticamente, pero apuntando al alto nivel de autoidentificación cultural que es necesario potenciar a través de los mecanismos previstos en el ordenamiento autonómico. Es, como no podía ser de otra manera, una apuesta política que urge a proteger, difundir y divulgar las expresiones culturales andaluzas como el modo más eficaz para que los valores democráticos y los diálogos interculturales se realicen de forma igualitaria.

En el segundo capítulo, Miguel Ropero describe y valora el habla andaluza desde su extrema variedad y riqueza sociolingüística. Tras caracterizarlo por su diferenciación acusada frente al español, su alta nivelación y su carácter vehicular en una tradición literaria de reconocido valor, profundiza en las polémicas sobre su carácter dialectal en contraste con el alto orgullo y conciencia de los andaluces. Un punto de partida que subraya las dificultades de homogenizar o reducir las características de las expresiones 
fónicas, morfosintácticas y léxicas en el andaluz. Aquí el planteamiento responde a los derechos recogidos en la Constitución Española de 1978 para la protección y difusión de las modalidades lingüísticas, con los establecidos en el Estatuto de Autonomía y con el sentimiento de los andaluces hacia su habla. A las dificultades para normativizar un espacio plural de matices, con rasgos propios muy marcados, se añade la polémica sobre su codificación ortográfica. El autor expone cómo la belleza fonética del andaluz se resiente al intentar atrapar en la escritura dejes, acentos, modulaciones y expresiones andaluzas. Una pluralidad de hablas que ha dejado su impronta en el español americano mostrando la universalidad de lo particular, la importancia del legado histórico y del contacto con otras culturas. Una cuestión de interés sería contar con las experiencias y propuestas alternativas que, actualmente, desde la reivindicación del andaluz pretenden aumentar el orgullo hacia el habla andaluza más allá de su conveniencia lingüística.

Juan Agudo, gran conocedor de los paisajes y los espacios, ha dedicado a la arquitectura tradicional una extensa tipología sobre los usos y formas con la que los andaluces han creado paisajes de sociabilidad. Sin afán de exhaustividad se detallan aspectos culturales, materiales y técnicas de construcción que permiten captar la especificidad de los lugares andaluces. La creatividad de las formas no es independiente de su funcionalidad en relación con las experiencias históricas y la imbricación con los modelos ecológicos y productivos que han cristalizado en una arquitectura para vivir, según la propia expresión del autor, en las comarcas de Sierra de Aracena, el Marquesado de Zenete y las Alpujarras. Desde las gañanías a las chozas, de las cuevas a las torrucas, la relación con la tierra andaluza se presenta con esta descripción vívida de las condiciones populares sin recurrir a la fotografía que, como técnica, se menciona en la introducción. La imposibilidad de incluirlas en este artículo se suple con una redacción muy visual y descriptiva. El análisis que presenta Agudo cabe destacar por la imbricación entre las formas, las funciones y los lugares que han marcado una tradición arquitectónica propia que ahora se encuentra en peligro de desaparición.

Manteniendo el interés por las formas andaluzas de sociabilidad, Javier Escalera se centra en las relaciones de poder y la cultura política. La selección realizada se basa en la significación y relevancia de estos marcadores en un contexto más amplio que se delimita en primer lugar. La importancia de los espacios públicos, el predominio de vínculos de carácter informal son rasgos destacables que convierten en lugares, en el sentido de Marc Augé (1993), los espacios y tiempos andaluces. Escalera destaca cómo, la situación de dependencia respecto al Estado Español provocó un mayor retraso en la aparición y desarrollo del asociacionismo voluntario moderno así como una menor importancia cuantitativa. Dentro de las estructuras de sociabilidad formalizadas son los aspectos cualitativos los que subrayan la especificidad andaluza: la relevancia de las cofradías y hermandades ha sido poco valorada en otras investigaciones por una estrecha y débil 
valoración del asociacionismo religioso vinculado al pasado. Como destaca Escalera, la vitalidad y adaptación de estas expresiones culturales pone de manifiesto su capacidad para aglutinar funciones latentes o no, con un fuerte peso de la localidad. Las relaciones de poder entroncan con los rasgos estructurales apuntados por Moreno en el primer capítulo: la fuerte personalización que fomenta líderes carismáticos, la importancia del marco local, la igualdad que se asocia con planteamientos izquierdistas y la desconfianza en el poder institucionalizado. De ahí el desenvolvimiento de identificaciones colectivas en ámbitos que se instrumentalizan para la expresión de una voluntad política mermada por las lógicas y estrategias de control estatales. Escalera señala la responsabilidad de los grupos que en lugar de fomentar la reorganización territorial y política de Andalucía han ido debilitando el marco autonómico.

El capítulo quinto examina las fiestas andaluzas mediante la diferenciación entre hechos sociales totales y fiestas sectoriales, en función de su significación para los miembros de una sociedad. Los niveles de la significación de la Semana Santa, planteados por Isidoro Moreno en trabajos previos, se enriquecen de una revisión en la que los sentimientos y los significados son más acabados y precisos. El análisis sobre el papel que desempeñan las mujeres rompe con el androcentrismo que aún rodea las opiniones y estudios sobre esta cuestión. Frente a la supuesta marginalización histórica refleja los cambios experimentados desde una intensa participación de las mujeres en los siglos XVI y XVII hasta su posterior marginación a medida que se imponía la ideología burguesa. Las romerías, ferias, carnavales y otras expresiones festivas completan esta sección a cargo de Moreno y Agudo.

El flamenco, su valor patrimonial y su potencialidad expresiva es tratado a continuación por Cristina Cruces. Desde su etimología y sus orígenes sociales, Cruces ofrece una detallada caracterización de los rasgos y los estilos flamencos, acercando la complejidad musical de este arte andaluz. Su análisis vinculando las coplas con la familia y el trabajo, su revisión del protagonismo de hombres y mujeres así como las peculiaridades ligadas a la etnicidad se insertan dentro del marco teórico propuesto por Moreno. A la historia y evolución de sus manifestaciones culturales, añade una revisión fundamental sobre el papel de los rituales en el flamenco. Por último, conocedora de primera mano de los nuevos tiempos del flamenco nos aproxima a aspectos tan esenciales como la comercialización, la inclusión definitiva en las enseñanzas, la industria musical y el efecto de las tecnologías. Un flamenco, el actual, que está demostrando una fuerte vitalidad y una enorme capacidad de adaptación para seguir expresando la cultura andaluza. Queda por saber si los apoyos políticos que han fomentado esta eclosión podrían provocar el mismo efecto en los ámbitos más desprotegidos de patrimonio cultural andaluz.

Esther Fernández de Paz aborda la economía y las culturas de la artesanía en el último capítulo. Una producción que también está sujeta a modificaciones de gran interés 
tanto desde el punto de vista legislativo, con la protección y el fomento de unos trabajos manuales que ya se contemplan en una ley propia, como por las nuevas demandas y oficios entre los sectores más jóvenes de la población. El creciente peso económico y su valor patrimonial están reorganizando las estructuras museológicas con experiencias más vivenciales y cercanas a los procesos de trabajo. Fernández de Paz define minuciosamente el concepto de artesanía, sus prácticas y clasificaciones, valorizando los contextos y los procesos históricos. La adaptabilidad al sistema económico vigente supuso reajustes en la fabricación, destino y aprendizaje además de resignificaciones en la propia consideración del artesano o en las relaciones entre éstos y los consumidores. Un epígrafe aparte merece el papel de las administraciones públicas que si bien han acabado potenciando a la Consejería de Turismo, Comercio y Deporte, por la viabilidad económica de estos trabajos manuales, en opinión de la autora, debería mantener definiciones y propuestas más culturales. La necesidad de documentar y recuperar las manifestaciones artesanales andaluzas, incluyendo aquellas sin ánimo de lucro, impulsar nuevas actividades artesanas, potenciar su enseñanza y divulgación no puede ser ajeno a sus niveles de significación cultural.

Desde esa centralidad de la cultura, los ejes que aúnan esta selección de textos escritos desde y por Andalucía suponen romper con los moldes bienpensantes y acomodaticios de una globalidad falsamente homogénea, resaltar y criticar los intereses dominantes, la imposición de ritmos y lugares en la producción del conocimiento. Expresiones Culturales de Andalucía evidencia que los pueblos dominados saben mantener su tradición, con una decidida voluntad de resistencia, adaptándose e incorporando las nuevas características de nuestro momento histórico. Ser andaluz es el resultado de un legado histórico y de una enculturación determinada. Un acto personal y colectivo que se expresa en la vida cotidiana y en la configuración de un pueblo como sujeto de derecho. Es también una proyección de futuro, una línea de acción que resume las vivencias y las formas andaluzas con su multiplicidad de significados. En suma, un libro imprescindible para continuar avanzando en y por Andalucía. 


\section{REFERENCIAS BIBLIOGRÁFICAS}

Augé, Marc (1993) Los "no lugares": espacios del anonimato. Una antropología de la sobremodernidad. Barcelona: Gedisa.

Castells, Manuel (1998) La era de la información. Economía, sociedad y cultura. El poder de la identidad Vol. II. Madrid: Alianza Editorial.

García Canclini, Néstor (2011) “De la diversidad a la interculturalidad”. En Néstor García Canclini (coord) Conflictos interculturales. Barcelona: Gedisa, pp.103-113.

MacKinnon, Catherine (1995) Hacia una teoría feminista del Estado. Madrid: Cátedra.

Moreno, Isidoro (1991) "Identidades y rituales. Estudio introductorio". En Joan Prats, Ubaldo Martínez, Jesús Contreras e Isidoro Moreno (eds) Antropología de los Pueblos de España. Madrid: Taurus, pp. 601-636. 